\title{
Impact of Uncertain Work Environment on Employee Job Performance in Banking Industry: A Perspective from Job Demands-Resources Model
}

\author{
Tabitha Eliaba Kenyi ${ }^{1 *} \quad$ Flora August Kimathi ${ }^{2 *} \quad$ Lodu Bosco John $^{3}$ \\ 1.Doctorate Program, School of Management, Huazhong University of Science \& Technology, Wuhan, Hubei \\ 430074, P. R of China \\ 2.College of Public Administration, Huazhong University of Science \& Technology, Wuhan, Hubei 430074, P. \\ $\mathrm{R}$ of China \\ 3.Master Program, School of Electronic Information and Communications, Huazhong University of Science \& \\ Technology, Wuhan, Hubei 430074, P. R of China
}

\begin{abstract}
With a focus on the Job Demands - Resources model (JD-R model), this paper examine the effect of the uncertain work environment (UWE) as an independent variable to explore the relationship between the job demands (JD) as moderating variable and job resources (JR) the mediator on employee job performance (JP). Commercial Banks of South Sudan employees were investigated through the distribution of 256 questionnaires, and 160 questionnaires were returned, which formed a response rate of $62.5 \%$. The study hypothesized that; H1. The uncertain work environment has a negative influence on employee work performance, H2. Uncertain work environment affects job resources negatively, H3. Job resources have a positive impact on employee work performance, H4. Job demands moderate the effect of job resources on work performance, H5. Job demands moderate the influence of uncertain work environment on job resources and H6. Job demands moderate the impact of the uncertain work environment in work performance. Results confirm that (UWE) affect the (JP). They have a significant negative influence on (JP), (JR) has a substantial impact with (JP), (JD) had a significant negative influence on relationship between (UWE) and (JP)through (JR), and (JD) moderate the impact of (UWE) on (JR) positively.
\end{abstract}

Keywords: Uncertain Work Environment, Job Demands, Job Resources, Job Performance, JD-R model, Commercial Banks of South Sudan

DOI: $10.7176 / \mathrm{EJBM} / 12-5-07$

Publication date: February $29^{\text {th }} 2020$

\section{Introduction}

The success and the failure of any organization depend on how it maintains the working environment which is the most vital element (Journal, Management, \& Global, 2002) in the productivity and job performance process, as an outcome of the employee engagement (Xanthopoulou, Bakker, Demerouti, \& Schaufeli, 2007). Work environment means all surroundings of entire industries that consist of many factors that include physical, social, technological, and even political. It can be a good/healthy environment (positive) or bad/unhealthy environment (negative) (Kossek, Kalliath, \& Kalliath, 2012). Many studies had been done on how the work environment affects employee job performance. This research paper is conducted to shed light on how uncertain work environment with the moderating of Job demands and mediating of Job Resources have a great impact on employee job performance in Banking Industry, especially in the post-war countries specifically in South Sudan. The researcher selected the Banking Industry because the banking sector is the most industry that enjoying a healthier work environment. This paper studying uncertainty work environment due to the lack of the research done in such areas characterized by poor and low productivity; to find out how the countries in which its employees experience uncertain work environment in carrying out their performances as a result of work engagement. (Anand \& Madhuvanthi, 2012) confirm the effectiveness of the work environment in combating performance. Thus, job performance is referred to as a deed of performing a task. It means to achieve an objective in a task, role, and firm; however, it is not the real results of activities that are undertaken in a job. Hence, this makes job performance to be different from other concepts like public performance, firm performance, which are more complex variables (Fleeson et al., 2017). Employee work engagement had been given a special focus for the last three decades to measure how much an individual contributes to her/his industry; according to studies, it is the main factor for job performance when employees are satisfied (Aziri, 2011). Even though employee engagement is a burning issue of the organizations or industries, special consideration is paid in the study for its outcome, which is the job performance. Job performance has never been conducted in South Sudan, where the work environment is a real disaster due to the crises the country is going through and turns the work situation in an uncertain work environment. Employee job performance needs full submission of employees emotionally, cognitively, and physically, according to the given job (Duggirala, Mehta, Kambhatla, \& Arya, 2012), (Anand \& Madhuvanthi, 2012). Therefore, the researchers 
reflect an uncertain work environment in addition to some constructs of both the job demands and job resources as variables to measure employees' job performance of commercial banks in South Sudan. The purpose of this article is: (1) to find out relationship between the uncertain work environment and job performance in the context of South Sudan, (2) to investigate whether the performance factors differ across the different level of management, (3) to explore the role of uncertain work environment from the perspective of the job demands-resources model. The method used in this research is quantitative method; to study the relationship between the uncertain work environment, job demands, and job resources (Dul, Ceylan, \& Jaspers, 2011). SPSS as a tool of the analysis; used for computing and testing the hypothesis: H1. The uncertain work environment has a negative influence on employee work performance, H2. Uncertain work environment affects job resources negatively, H3. Job resources have a positive influence on employee job performance, H4. Job demands moderate the effect of job resources on job performance, H5. Job demands moderate the influence of uncertain work environment on job resources and H6. Job demands moderate the effect of the uncertain work environment in job performance

\section{Job Performance}

Job performance is referred to as a deed of performing a task. It means to achieve an objective in a task, role, and firm; however, it is not the real results of activities that are undertaken in a job. Hence, this makes job performance to be different from other concepts like public performance, firm performance, which are more complex variables (Fleeson et al., 2017) (Wolfe et al., 1990) (Campbell \& M1, 2007). Further, Campbell posits that work performance is not a singular act, but it is a complex task. Job performance is mainly a behavior that is different from the consequences of a certain job that is associated with productivity and success. Work performance can be referred to as values and overall benefits that an organization gets from its workers in a certain duration of time (Motowidlo \& Scotter, 2015). Carlson (2006) refers to work performance as accomplishing tasks by workers in line with prescriptions provided by the firm management, whereas using the provided resources in a turbulent environment.

\section{1 definition of Job Performance}

Many scholars paid attention to the study of Job performance. Therefore, different perspectives had been registered in the definition of the term. (Rotundo \& $\mathrm{Ph}, 2002$ ) defined job performance as the acts and behaviors under individuals' control, and they contribute to the firm objectives. Further, job performance is the creation of value through employee's performance behavior over a period of time. The implication is that JP is adopted to determine the extent to which works perform tasks given to them (Trudel, 2009).

Conversely, (Grossman et al., 1989), posits that systems of job performance should be built on the behavior of employees rather than the behavioral outcomes. Also, Murphy noted that stressing on outcomes may influence workers to come with a secure method to attain pre-determined consequences that are harmful to the company in the long run. Accordingly, (Grossman et al., 1989) and (Wolfe et al., 1990) had a similar opinion on that performance ought to be seen as the consequences of certain behaviors, and job performance can be perceived as observable behaviors that employees are engaged on it.

\subsection{Concept and Forms of Job Performance}

Generally, job performance is a person's contribution to the overall success of the firm. The factors are distinct based on the framework that is applied (Flenady et al., 2009). Nonetheless, the scientific community widely agrees that the performance of jobs consists of two key factors, which are the performance of tasks and well as contextual performance (Motowidlo \& Scotter, 2015).

Job performance can be either in the form of task performance, which is the basic component of performance appraisal as it conducts a direct assessment of task results and relates to the effectiveness of tasks influencing organizations' technical core (Rotundo \& $\mathrm{Ph}, 2002$ ). Or in the form of contextual performance, which refers to how able employees are in contributing to general organizational well-being. In the recent past, contextual performance has been considered to be crucial in the overall performance of tasks. Job performance is significant to employees because it indicates the level of efficacy, high performance, mastery, and elicits feelings to job satisfaction, (Performance, Heggestad, \& Kanfer, 2005). Consequences of job performance are defined as the observable, quantifiable measurements that show the level of progress achieved by an individual or an organization.

\section{Uncertain Work Environment}

The uncertain work environment is the main variable in the study. It emerges when situation details are complicated, unpredictable, or problematic, then we say uncertainty exists; the case is similar when there is information unreliability or inconsistency; or the feeling of insecurity in knowledge state in general (Herzig et al., 2011). Due to the dynamic nature of the organizational environment,' uncertain work environment is inevitable and became great challenging, that organizations are forced to deal with, to be successful. Therefore, uncertainty in the business environment is an external force that is beyond the control of the management but affects the performance of employees (Mcmullen \& Shepherd, 2006). According to the researcher, such an environment is 
not experienced in all countries; still, it could be experienced only by post-war countries, so the Republic of South Sudan is the leading country which is going through an uncertain or insecure environment. Therefore, the banking industry to be the sector of the study. The uncertain work environment is causing unpleasant experiences. Besides, it can affect the behavior of employees; the behavior of low self-actualization reinforces uncertainty, and the result is the development of negative character traits in employee behavior. Furthermore, as a strategy to survive in an uncertain work environment, sensible and responsible employees can change to irresponsible and irrational (Kim \& Byon, 2018); due to the situation of struggling for a living. The study finds that an uncertain work environment affects the daily job performance schedule, no stability in the office, from another side, some customers not respecting and want to force staff of the bank to do according to their will. The intervention of some parts while performing their duties especially the shareholders, the dispute among people, implementing policies that come from above such as the board of director even though is not according to the policy

\section{Job Resources and Job Demands}

Anything that an individual received and helped them in attaining their goal is said to be resources (Halbesleben, Neveu, \& Westman, 2015). Physical, psychological organizational, or social aspects of the job that reduce costs or demands are defined to be job resources, and they help an individual or an organization to achieve work goals, individual growth, and learning and development. Therefore, aside from resources being important in dealing with job demands and getting things done, it is in their own right important (Hobfoll, 2014). Therefore, resources are important in enabling employees to complete their tasks and goals successfully and are also a means of enhancing their performance capacity and well-being (Balducci \& Schaufeli, 2011). Job demands refer to factors of a job that require continuous physical and psychological effort or skills and consume certain physiological or psychological costs (Bakker \& Demerouti, 2007). In this study, three job demands have been selected; work pressure, disturbances, and emotion at work to reflect the job performance of employees in the banking industry in South Sudan. As pointed out in the previous studies that, three job demands have been identified high workload, time pressure and work-family conflict (van den Broeck, de Cuyper, de Witte, \& Vansteenkiste, 2010); (Fleeson et al., 2017) (Halbesleben et al., 2015). All three demands influence employee performance. As workers' job demands increase, physiological and psychological resources are increasingly drained (Demerouti, Mostert, \& Bakker, 2010). That causes negative work outcomes if enough essential resources of individuals are not available (Molino, Bakker, \& Ghislieri, 2016), (Demerouti, Nachreiner, Bakker, \& Schaufeli, 2001). these studies suggest that job demands could cause job burnout. (van den Broeck et al., 2010) found that job demands cause emotional exhaustion, and under circumstances of high job demands, the constant consumption of employees' resources leaves them unable to cope with these demands. Consequently, task difficulty increases and work enthusiasm declines, increasing the likelihood of absenteeism and absence (van Woerkom, Bakker, \& Nishii, 2016). So, this paper found the situation of the employee job performance in commercial banks of South Sudan, similar to the previous studies. Thus, the positive reaction of the employee in job performance is a result of well-being (Nielsen et al., 2017). Therefore, the well-being and emotional understanding of an employee are essential factors for job performance (Dicke, Stebner, Linninger, Kunter, \& Leutner, 2018). Conferring to study by Konrad in 2006; engaged employees are see-through their unrestricted behavior (Ngao \& Mwangi, 2013);(Anand \& Madhuvanthi, 2012). In this study, employees of the banking industry in South Sudan revealed the motive of their job performance depends on, as the first priority is prevailing of the peace and security then, availability of the job resources and job demands, which in turn will motivate them to perform well.

\section{4. methodology}

The researchers applied the purposive sampling procedure to identify and select commercial banks within Juba; the capital city of South Sudan, 256 respondents were issued with questionnaires, but only 160 questionnaires were received. Therefore, response results formed a response rate of $62.5 \%$, and SPSS used to analyze. According to Hinton, Brownlow, McMurray, and cozens (2004) an alpha value of 0.75 and above indicates a high reliability, while values of 0.5 to 0.75 are acceptable as they indicate moderate reliability. Therefore, all variables were included in the study since they met reliability threshold; all variables had Cronbach alpha values greater than 0.6 which indicate that the reliability is acceptable.

\section{Table1: Reliability Analysis}

\begin{tabular}{ll}
\hline Variable & Cronbach's Alpha \\
\hline Job Demands & .658 \\
Job Resource & .691 \\
Uncertainty Work Environment & .618 \\
Employee Job Performance & .686 \\
\hline
\end{tabular}

The study encompassed gender, age, educational level, marital status, and type of the organization to gather general information of the respondents; the result obtained that, $(66 \%)$ of the respondents used in the study were male while 34\% were female; $60.6 \%$ were born between the year 1980 and 1989 an indication that they were aged 
between 31 and 41 years old, 18.1\% were born in between 1990 and 1999 an indication they were aged between 20 and 29 years, another $18.1 \%$ were born between 1970 and 1979, and 3.1\% indicated that they were born before 1960 an indication that they were aged 59 years and above; $(73.1 \%)$ of the respondents were married, $25.6 \%$ were single, and $1.3 \%$ was either widow or widower; $(76.9 \%)$ of the respondents selected for the study had university as their level of education, $11.9 \%$ had post-graduate, $1.9 \%$ had secondary school, and $0.6 \%$ had commercial school; $76.9 \%$ of the respondents worked at National/local bank while $23.1 \%$ worked at a foreign bank. The above mentioned percentage is an indication that National and Foreign Banks are not gender bias according to the South Sudan constitution which provides quota for women representation of $25 \%$ in all governmental institutions, and the analysis shows that young people are the majority in employment due to their educational level, therefore, they are active and responsible as the result of the taking family burden, it also indicated that the majority of employees are national citizens.

\section{Result}

5.1 Uncertain Work Environment Effect on Job Performance

The study complied multilevel regression; first regressed uncertain work environment on job performance to test the second part of the first objective, which was; to find out the relationships between the uncertain work environment and employee performance in the context of South Sudan. The result is shown in table 1;

Table 1: Model Summary for Uncertain Work Environment on Performance

\begin{tabular}{lcccc}
\hline Model & R & R Square & Adjusted R Square & Std. Error of the Estimate \\
\hline 1 & $.603^{\mathrm{a}}$ & .364 & .360 & .71119 \\
\hline a. Predictors: & (Constant) & uncertain work environment &
\end{tabular}

a. Predictors: (Constant), uncertain work environment

The study finds the value of R2 is 0.364 , which is an indication that $36.4 \%$ of changes in job performance can be attributed to changes in an uncertain work environment.

Table 2: ANOVA for Uncertain Work Environment on Job Performance

\begin{tabular}{llccccc}
\hline Model & Sum of Squares & df & Mean Square & F & Sig. \\
\hline \multirow{2}{*}{1} & Regression & 45.751 & 1 & 45.751 & 90.453 & $.000^{\mathrm{b}}$ \\
& Residual & 79.916 & 158 & .506 & & \\
& Total & 125.666 & 159 & &
\end{tabular}

a. Dependent Variable: performance

b. Predictors: (Constant), uncertain work environment

ANOVA was computed to test whether the model obtained was significant. The model significance was tested at a $5 \%$ level of significance. From the findings, the p-value obtained $(0.000)$ was less than the selected level of significance (0.05), which is an indication that the model developed was significant. The findings further showed that the f-calculated value (90.453) was higher than the f-critical value obtained from the f-distribution tables $(\mathrm{F} 1,158=3.901)$, which is an indication that an uncertain work environment influences job performance

\section{Table 3: Coefficients for Job Resources on Job Performance}

\begin{tabular}{llccccc}
\hline Model & \multicolumn{2}{c}{$\begin{array}{c}\text { Unstandardized } \\
\text { Coefficients }\end{array}$} & \multicolumn{2}{c}{$\begin{array}{c}\text { Standardized } \\
\text { Coefficients }\end{array}$} & \multirow{2}{*}{ Sig. } \\
\cline { 2 - 5 } & \multicolumn{2}{c}{ B } & Std. Error & Beta & & \\
\hline \multirow{2}{*}{1} & (Constant) & 6.094 & .219 & & 27.867 & .000 \\
& Uncertain work environment & -.688 & .072 & -.603 & -9.511 & .000
\end{tabular}

a. Dependent Variable: performance

From the coefficients table, the unstandardized beta coefficients values were used to fit the following regression model;

From the beta coefficients table, the following regression model was developed;

$\mathrm{Y}=\mathbf{6 . 0 9 4}-\mathbf{0 . 6 8 8} \mathrm{X}+\varepsilon$

( $\mathrm{Y}$ is Job Performance, and $\mathrm{X}$ is an uncertain work environment).

From the above regression equation, it is evident that holding an uncertain work environment to a constant zero, job performance will be at a constant value of 6.094. The findings further established that an uncertain work environment has a negative influence on job performance $(\beta=-0.688)$. Also, the $p$-value for the beta coefficient was 0.000 , which is less than a selected level of significance (0.05). Therefore, an uncertain work environment had a significant negative influence on job performance.

The first hypothesis of the research was H1. The uncertain work environment has a negative influence on employee job performance. Based on the results presented above, the study failed to reject the null hypothesis and concluded that an uncertain work environment negatively influences employee job performance. 
results were used to test the second and third research hypothesis; H2. Uncertain work environment affects job resources negatively, and $\boldsymbol{H} 3$. Job resources have a positive influence on employee work performance The first part of the findings shows the findings on the influence of independent variable on job resources and the following equation was found;

M= 4.4981 - .4031X (M=Job Resources, $\mathrm{X}$ uncertain work environment)

The above model was found to be significant since the $p$-value of the model summary was (.000) was less than the selected level of significance (0.05). Results indicated above also show that an uncertain work environment was a significant predictor of job resource, $\beta=-.4031, \mathrm{SE}=.0808, \mathrm{p}<.05$. Based on the findings, the study failed to reject the second null hypothesis $\boldsymbol{H} \mathbf{2}$ and concluded that an uncertain work environment harms job resources.

The findings also showed the effects of the mediating and the independent variables on employee job performance. From the findings, the following regression model was developed;

$\mathrm{Y}=\mathbf{4 . 1 0 0 2}-\mathbf{. 4 9 5 \mathrm { X }}+\mathbf{. 4 2 9} \mathrm{M}(\mathrm{Y}=$ Job performance, $\mathrm{X}$ uncertain work environment, and $\mathrm{M}=\mathrm{J}$ ob resources).

The above model was significant since the p-value (.000) from the model summary was less than a selected level of significance (0.05). From the preceding equation, it can be observed that job resources have a positive influence on employee work performance $(\beta=.429, \mathrm{SE}=.0652, \mathrm{p}<.05)$. These results support the third hypothesis, $\boldsymbol{H 3}$, that job resources have a positive influence on employee job performance.

Furthermore, the findings show that an uncertain work environment was still a significant predictor of job performance after controlling for a mediator, job resource $(\beta=-.495, \mathrm{SE}=.0713, \mathrm{p}<0.05)$. From the model summary, approximately $48 \%$ of the variance in job performance was explained by the predictors (uncertain work environment and job resources), as indicated by the R2 value of .4799 . The direct and indirect effects were tested using a percentile bootstrap estimation approach with 1000 samples (Kenny, Korchmaros, \& Bolger, 2003), implemented with the PROCESS macro Version 3.4 (Hayes, 2019). These results indicated the direct coefficient was significant, $\beta=-.495, \mathrm{SE}=.0713,95 \% \mathrm{CI}=-.6358,-.3542$. The uncertain work environment was associated with employee job performance with scores approximately -.1729 less when mediated by job resources.

\subsection{Moderating Effect of Job Demands}

The effect of job demands is termed as an interaction that affects the direction or strength of the relationship between job performance and an uncertain work environment. The effect of the moderating variable was tested by computing the moderated mediated analysis with model 59 of PROCESS macro (Hayes, 2013). The results obtained guided the study in answering the following research hypothesis; H4. Job demands moderate the effect of job resources on work performance, H5. Job demands moderate the influence of uncertain work environment on job resources and H6. Job demands moderate the effect of the uncertain work environment in work performance. The findings show how job resources are affected by the independent variable, the moderating variable, and the interaction between the independent and the moderating variables (uncertain $*$ job demands). From the findings, the following regression equation was developed;

$\mathrm{M}=6.5147-\mathbf{9 6 5 7} \mathrm{X}-\mathbf{. 6 6 6 9} \mathrm{W}+\mathbf{. 1 7 7 1 X W}(\mathrm{M}=$ Job Resources, $\mathrm{X}=$ uncertain work environment, $\mathrm{W}=$ job demand, $\mathrm{XW}=$ uncertain work environment $*$ job demands)

The above model was significant since the p-value (.000) in the model summary was less than the selected level of significance (0.05). From the findings, an uncertain work environment had a significant influence on job resources $(\beta=-.9657, \mathrm{SE}=.228, \mathrm{p}<0.05)$. Job demand is also seen to have a significant influence on job resources $(\beta=-.6669, \mathrm{SE}=.2354, \mathrm{p}<0.05)$. These findings show that an uncertain work environment and job demand have a significant negative influence on job resources. The study, therefore, accepted the null hypothesis $\boldsymbol{H} \boldsymbol{4}$ and concluded that job demands moderate the effect of job resources in work performance.

The findings further showed that the interaction term (uncertain work environment $*$ job demands) had significant influence on job resources $(\beta=.1771, \mathrm{SE}=.0634, \mathrm{p}=0.0059<0.05)$. This finding shows that the interaction term positively and significantly influences job resources. Based on the research findings, the study failed to reject the fifth research hypothesis $(\boldsymbol{H 5})$ and concluded that job demands moderate the influence of uncertain work environment on job resources

Furthermore, on the conditional effect of the focal predictor (uncertain work environment) at a different value of moderator (job demands), the findings showed that at low levels of job demands (2.1818), the effect is low (-.5792). In contrast, at high levels of job demands (3.3636), the effect is high (-.3699). Therefore, an increase in job demands causes a greater effect on job resources.

\section{Discussion}

The study was designed to find out the relationships between the work environment in the form of an uncertain work environment and job performance in the context of South Sudan. It revealed that job resources, job demands, and job performance are strongly related, and it established that, with the introduction of job demands as moderating variables on the relationship between uncertain work environment and job performance, job demands have a positive influence on the relationship. At the very time, there is a strong positive relationship existing 
between job resources and employee job performance, where job resources had a significant positive influence on employee job performance. The research was to examine the role of uncertain work environment from the perspective of the Job Demands-Resources Model; findings showed that there is a positive relationship existing between uncertain work environment and employee job performance through job resources. It is also evident that an uncertain work environment has negative effects on employees' daily work life through interruptions they encounter. Because of the same uncertainties, they are forced to perform tasks outside established systems. Therefore, an uncertain work environment affects the daily work schedule of National and Foreign Commercial Banks of South Sudan.

\section{Conclusion}

The study set out that, uncertain work environment had a significant negative impact on job performance and a negative effect on job resources. Job resources positively related to employee job performance, and the influence was significant. At the same time, it established that the moderating variable of job demands had a negative influence on the relationship between an uncertain work environment and employee job performance through job resources. The influence was found to be significantly negative, and job demands moderate the influence of uncertain work environment on job resources positively. In conclusion, the study observed uncertain work environment as a variable factor that have an impact on job demand-resources model, and the study also put some policies implications to improve the banking industry in South Sudan.

\section{References}

Anand, V. V., \& Madhuvanthi, K. (2012). A Study on the Employee Engagement with Special reference to CPCL, 25-30.

Aziri, B. (2011). JOB SATISFACTION: A LITERATURE REVIEW, 3(4), 77-86.

Bakker, A. B., \& Demerouti, E. (2007). The Job Demands-Resources model: State of the art. Journal of Managerial Psychology, 22(3), 309-328. https://doi.org/10.1108/02683940710733115

Balducci, C., \& Schaufeli, W. B. (2011). European Journal of Work and Organizational Psychology The job demands-resources model and counterproductive work behavior: The role of job- related affect, (July).

Campbell, K., \& M1, A. (2007). Gender Diversity in the Boardroom and Firm Financial Performance. https://doi.org/10.1007/s10551-007-9630-y

Demerouti, E., Mostert, K., \& Bakker, A. B. (2010). Burnout and Work Engagement: A Thorough Investigation of the Independency of Both Constructs. Journal of Occupational Health Psychology, 15(3), $209-222$. https://doi.org/10.1037/a0019408

Demerouti, E., Nachreiner, F., Bakker, A. B., \& Schaufeli, W. B. (2001). The job demands-resources model of burnout. Journal of Applied Psychology, 86(3), 499-512. https://doi.org/10.1037/0021-9010.86.3.499

Dicke, T., Stebner, F., Linninger, C., Kunter, M., \& Leutner, D. (2018). A longitudinal study of teachers' occupational well-being: Applying the job demands-resources model. Journal of Occupational Health Psychology, 23(2), 262-277. https://doi.org/10.1037/ocp0000070

Duggirala, M., Mehta, S., Kambhatla, N., \& Arya, P. (2012). Employee engagement: Conceptual model and computation framework. Annual SRII Global Conference, SRII, 850-858. https://doi.org/10.1109/SRII.2012.111

Dul, J., Ceylan, C., \& Jaspers, F. (2011). Knowledge workers' creativity and the role of the physical work environment. Human Resource Management, 50(6), 715-734. https://doi.org/10.1002/hrm.20454

Fleeson, W., Jayawickreme, E., Jones, A. B. A. P., Brown, N. A., Serfass, D. G., Sherman, R. A., ... Matyjek-, M. (2017). No \{Title\}. Journal of Personality and Social Psychology, 1(1), 1188-1197. https://doi.org/10.1111/j.1469-7610.2010.02280.x

Flenady, V., Koopmans, L., Middleton, P., Frøen, J. F., Smith, G. C., Gibbons, K., ... Ezzati, M. (2009). Major risk factors for stillbirth in high-income countries: a systematic review and meta-analysis. The Lancet, 377(9774), 1331-1340. https://doi.org/10.1016/S0140-6736(10)62233-7

Grossman, R. M., Krueger, J., Yourish, D., Granelli-piperno, A., Murphy, D. P., May, L. T., ... Gottlieb, A. B. (1989). psoriatic proliferation, 86(August), 6367-6371.

Halbesleben, J. R. B., Neveu, J., \& Westman, M. (2015). Getting to the "COR": Understanding the Role of Resources in Conservation of Resources Theory (July 2014). https://doi.org/10.1177/0149206314527130

Herzig, S. E., Jimmieson, N. L., Powell, M., Dunwoody, S., Griffin, R., Neuwirth, K., ... Neuwirth, K. (2011). Middle managers' uncertainty management during organizational change. https://doi.org/10.1108/01437730610709264

Hobfoll, S. E. (2014). Social and Psychological Resources and Adaptation (December 2002). https://doi.org/10.1037/1089-2680.6.4.307

Journal, P., Management, F., \& Global, I. (2002). The impact of office environments on employee performance: The design of the workplace as a strat ... 
Kenny, D. A., Korchmaros, J. D., \& Bolger, N. (2003). Lower Level Mediation in Multilevel Models, 8(2), 115128. https://doi.org/10.1037/1082-989X.8.2.115

Kim, K., \& Byon, K. K. (2018). A mechanism of mutually beneficial relationships between employees and consumers: A dyadic analysis of employee-consumer interaction. Sport Management Review. https://doi.org/10.1016/j.smr.2018.01.003

Kossek, E. E., Kalliath, T., \& Kalliath, P. (2012). Achieving employee well-being in a changing work environment: An expert commentary on current scholarship. International Journal of Manpower, 33(7), 738-753. https://doi.org/10.1108/01437721211268294

Mcmullen, J. S., \& Shepherd, D. A. (2006). ENTREPRENEURIAL ACTION AND THE ROLE OF UNCERTAINTY IN THE THEORY OF THE ENTREPRENEUR, 31(1), 132-152.

Molino, M., Bakker, A. B., \& Ghislieri, C. (2016). The role of workaholism in the job demands-resources model. Anxiety, Stress, and Coping, 29(4), 400-414. https://doi.org/10.1080/10615806.2015.1070833

Motowidlo, S. J., \& Scotter, J. R. Van. (2015). Evidence That Task Performance Should Be Distinguished From Contextual Performance, (October). https://doi.org/10.1037/0021-9010.79.4.475

Ngao, E., \& Mwangi, C. (2013). Effects of Managing Gender of Employees in Enhancing Organizational Performance. A Case Study of Kenya Ports Authority, 5(21), 1-8.

Nielsen, K., Nielsen, M. B., Ogbonnaya, C., Känsälä, M., Saari, E., \& Isaksson, K. (2017). Workplace resources to improve both employee well-being and performance: A systematic review and meta-analysis. Work and Stress. https://doi.org/10.1080/02678373.2017.1304463

Performance, T. P., Heggestad, E. D., \& Kanfer, R. (2005). The Predictive Validity of Self-Efficacy in Training Performance: Little More The Predictive Validity of Self-Efficacy in Training Performance: Little More Than Past Performance, (July). https://doi.org/10.1037/1076-898X.11.2.84

Rotundo, M., \& Ph, D. (2002). No Title, (September), 1-72.

van den Broeck, A., de Cuyper, N., de Witte, H., \& Vansteenkiste, M. (2010). Not all job demands are equal: Differentiating job hindrances and job challenges in the job demands-resources model. European Journal of Work and Organizational Psychology, 19(6), 735-759. https://doi.org/10.1080/13594320903223839

van Woerkom, M., Bakker, A. B., \& Nishii, L. H. (2016). Accumulative job demands and support for strength use: Fine-tuning the job demands-resources model using conservation of resources theory. Journal of Applied Psychology, 101(1), 141-150. https://doi.org/10.1037/ap10000033

Wolfe, F., Smythe, H. A., Yunus, M. B., Bennett, R. M., Bombardier, C., Goldenberg, D. O. N. L., ... Sheon, R. P. (1990). THE AMERICAN COLLEGE OF RHEUMATOLOGY 1990 CRITERIA FOR THE CLASSIFICATION OF FIBROMYALGIA Report of the Multicenter Criteria Committee.

Xanthopoulou, D., Bakker, A. B., Demerouti, E., \& Schaufeli, W. B. (2007). The role of personal resources in the job demands-resources model. International Journal of Stress Management, 14(2), 121-141. https://doi.org/10.1037/1072-5245.14.2.121

\section{Biography}

Tabitha Eliaba Kenyi, born in Khartoum - Sudan, (1 ${ }^{\text {st }}$ July 1974). A former Director of Center for Human Resources Development and Continual Education - University of Juba (May 2015 to January 2019), a lecturer in the college of Community Studies and Rural Development since 2004. Madam Kenyi has been an active member of civil society organizations, faith base organizations, and youth organizations. She works as secretary for social affairs for Working Women Association - UJ (2007 to 2014), a Coordinator of South Sudanese Women Leaders Coalition (2012 to 2013); under the umbrella of Institute of Inclusive Security - Washington DC; USA, Secretary of Young family Group ASC and A member of board of governance of the Episcopal University.

Tabitha obtained bachelor of science in Organizational Management from Ahfad University for Women - Sudan (December 1996), Master of Arts in Rural Development from University of Juba - Sudan (December 2004), currently she is a PhD candidate, Major is Management Science and Engineering at Huazhong University of Science and Technology - Wuhan; People's Republic of China since 2017.

Flora August Kimathi; graduated from Mzumbe University (2010), Morogoro -Tanzania, obtained Bachelor degree in Public Administration; Master's degree in Administrative Management, Huazhong university of science and technology (2014) - Wuhan; People's Republic of China, and PhD in E- Government, Huazhong university of science and technology (2019) - Wuhan; People's Republic of China.

Lodu Bosco John; graduated from University of Juba (2017), Juba -Republic of South Sudan, obtained Bachelor (Hons) degree in Information Technology; Currently perusing Master degree in Information and Communications Engineering at Huazhong university of science and technology- Wuhan; People's Republic of China since September 2018. 